\title{
Processos formativos online em tempos de pandemia: Promoção de diálogos sobre educação e ensino
}

\author{
Online training processes in times of pandemic: Promoting dialogues on education and teaching \\ Procesos de formación online en tiempos de pandemia: Promoviendo diálogos sobre educación y
} docencia

Recebido: 29/03/2021 | Revisado: 08/04/2021 | Aceito: 12/04/2021 | Publicado: 23/04/2021

\author{
José Francisco Zavaglia Marques \\ ORCID: https://orcid.org/0000-0002-7866-112X \\ Universidade Federal do Rio Grande Sul, Brasil \\ E-mail: franciscoquimica12@gmail.com \\ Keiciane Canabarro Drehmer-Marques \\ ORCID: https://orcid.org/0000-0002-5338-8534 \\ Universidade Federal de Santa Maria, Brasil \\ E-mail: keicibio@gmail.com \\ Sabrina Gabriela Klein \\ ORCID: https://orcid.org/0000-0001-5944-0754 \\ Universidade Federal de Santa Maria, Brasil \\ E-mail: sabrinaklein92@gmail.com \\ Diuliana Nadalon Pereira \\ ORCID: https://orcid.org/0000-0002-9895-1562 \\ Universidade Federal de Santa Maria, Brasil \\ E-mail: diulinadalon@gmail.com \\ Josiane Marques da Silva \\ ORCID: https://orcid.org/0000-0002-1283-4841 \\ Universidade Federal de Santa Maria, Brasil \\ E-mail: josimarquesilva@ gmail.com \\ Natiéle Medina Oliveira \\ ORCID: https://orcid.org/0000-0002-6700-3957 \\ Universidade Federal de Santa Maria, Brasil \\ E-mail: natielemedinaoliveira@gmail.com \\ Karine Gehrke Graffunder \\ ORCID: https://orcid.org/0000-0001-8860-9889 \\ Universidade Federal de Santa Maria, Brasil \\ E-mail: ka.graffunder@gmail.com
}

\begin{abstract}
Resumo
Este trabalho tem por objetivo apresentar e discutir novas possibilidades de espaço/tempo para formação de professores diante de um cenário mundial marcado pela pandemia da COVID-19. Apresentamos e analisamos o desenvolvimento de um projeto de extensão criado pela Representação Discente e demais colaboradores do Programa de Pós-Graduação Educação em Ciências: Química da Vida e Saúde da Universidade Federal de Santa Maria. O projeto promoveu Ciclos Formativos Online para professores por meio da plataforma do YouTube através do qual foram realizadas 44 lives tratando de diferentes temas voltados para a educação. O canal do YouTube atingiu 3.804 inscritos e as lives ocorreram com a participação de 58 palestrantes de todas as regiões brasileiras. O desenvolvimento do projeto durante o momento vivenciado de distanciamento físico permitiu diálogos e reflexões teóricas e práticas entre educadores sobre diversos aspectos, contribuindo com processos de reflexão e formação docente. Além disso, a utilização de tecnologias digitais favoreceu uma maior acessibilidade e praticidade pelos sujeitos participantes de diferentes locais, superando a necessidade da presencialidade.
\end{abstract}

Palavras-chave: COVID-19; Ensino; Ensino de ciências; Tecnologias digitais; Formação de professores.

\begin{abstract}
This work aims to present and discuss new possibilities of space / time for teacher training given a world scenario marked by the pandemic of COVID-19. We present and analyze the development of an extension project created by the Student Representation and other collaborators of the Graduate Program in Science Education: Life Chemistry and Health at the Federal University of Santa Maria. The project promoted Online Training Cycles for teachers through the YouTube platform through which 44 lives about different topics related to education. The YouTube channel reached 3,804 subscribers and the lives happened with the participation of 58 speakers from all Brazilian regions. The development of the project during the experienced moment of physical distance applied dialogues and
\end{abstract}


theoretical and practical reflections. reflections between educators on distinct aspects, contributing to processes of reflection and teacher training. In addition, the use of digital technologies enabled greater accessibility and practicality by participants from different locations, overcoming the need for presence.

Keywords: COVID-19; Teaching; Science teaching; Digital technologies; Teacher training.

\section{Resumen}

Este trabajo tiene como objetivo presentar y discutir nuevas posibilidades de espacio / tiempo para la formación docente ante un escenario global marcado por la pandemia de COVID-19. Presentamos y analizamos el desarrollo de un proyecto de extensión creado por la Representación de Estudiantes y otros colaboradores del Programa de Posgrado en Educación Científica: Química de la Vida y Salud de la Universidad Federal de Santa María. El proyecto impulsó Ciclos de Formación Online para docentes a través de la plataforma YouTube, a través de los cuales se realizaron 44 En Vivo, abordando diferentes temas relacionados con la educación. El canal de YouTube alcanzó los 3.804 suscriptores y las vidas se desarrollaron con la participación de 58 ponentes de todas las regiones brasileñas. El desarrollo del proyecto durante la experiencia de la distancia física permitió diálogos y reflexiones teóricas y prácticas entre los educadores sobre diversos aspectos, contribuyendo a procesos de reflexión y formación docente. Además, el uso de tecnologías digitales favoreció una mayor accesibilidad y practicidad por parte de los sujetos que participan en diferentes ubicaciones, superando la necesidad de presencia.

Palabras clave: COVID-19; Enseñanza; Enseñanza de las ciencias; Tecnologías digitales; Formación de profesores.

\section{Introdução}

\subsection{Apresentação e contexto do projeto}

Este trabalho visa relatar e analisar o desenvolvimento do projeto intitulado "Ciclos formativos de professores online: promoção de diálogos sobre educação", idealizado pela representação discente do Programa de Pós-Graduação em Educação em Ciências da Universidade Federal de Santa Maria (PPGECQVS/UFSM), juntamente com uma doutora egressa do programa e Técnica de Biologia da UFSM e um professor do PPGECQVS, em abril de 2020, após a suspensão das atividades presenciais no mês de março devido a pandemia da COVID-19. Diante desse contexto, criamos um canal no YouTube intitulado "Educação em Ciências UFSM" com objetivo de promover diálogos e interações entre os pós-graduandos com os demais professores da Educação Básica e do Ensino Superior, licenciandos e comunidade externa interessada em ouvir e discutir sobre temáticas da educação e do ensino. Após o registro do projeto, participamos de uma seleção de bolsas no 'Programa de prevenção e enfrentamento à COVID-19' realizada pela Pró-Reitoria de Extensão, na qual fomos contemplados com o auxílio de uma aluna bolsista pelo período de cinco meses.

Por meio do canal do YouTube, foram organizadas e mediadas lives por um grupo de estudantes integrantes da representação discente do PPGECQVS. As lives ocorreram semanalmente, de abril à novembro de 2020, e contaram com a participação de professores, pesquisadores e colaboradores de diferentes partes do Brasil, dialogando sobre temas da área do ensino ou da educação. Inicialmente, almejávamos o canal como um espaço de discussões e reflexões para os demais colegas do programa, uma vez que nesse período, a UFSM estava sem aulas devido ao contexto pandêmico e não havia um novo calendário previsto de retomada. Entretanto, como essa realidade se repetia em todo país, estudantes e professores de outras instituições começaram a conhecer e divulgar o canal, ampliando o alcance para outros sujeitos e regiões.

Os encontros foram transmitidos ao vivo através do canal pela plataforma YouTube. A interação dos participantes externos ocorria via chat, com atuação de um representante do projeto para esclarecer dúvidas e repassar questionamentos/reflexões ao mediador e convidados do ciclo formativo presentes. Os vídeos permaneceram salvos no canal para posterior visualização. A aceitação e a repercussão positiva do canal estimularam a criação de redes sociais, sendo estas um perfil no Instagram e uma página do Facebook, com o propósito de divulgar as lives.

Inicialmente, o projeto certificava apenas os palestrantes, porém, devido às solicitações e manifestações do público quanto à certificação, realizamos três ciclos de certificação aos participantes. Considerando o amplo alcance das lives a diferentes públicos e atividades realizadas durante esse período, além da necessidade dos encontros, esta pesquisa objetiva apresentar e discutir novas possibilidades de espaço/tempo para formação de professores na realidade pandêmica. 


\subsection{A COVID-19 e a reinvenção dos processos educativos por meio do ensino remoto}

A pandemia da COVID-19 surpreendeu a todos os setores em escala mundial e com o setor educacional não foi diferente, visto que, o ensino nos seus diferentes níveis foi atingido de forma repentina. A partir disso, recorreu-se ao uso de estratégias do Ensino Remoto Emergencial (ERE), estabelecido por Arruda (2020) como uma estratégia importante para manter o vínculo entre discentes, docentes e demais atores da educação. Ademais, o pesquisador destaca que o Brasil ainda não possui iniciativas frente às tecnologias para torná-las um saber necessário na formação dos estudantes, como já ocorre em outros países.

Diante do contexto atual, em que boa parte das atividades de ensino tornaram-se remotas, é necessário repensar as práticas educativas alicerçadas em Tecnologias Digitais de Informação e Comunicação (TDIC). As tecnologias agem como catalisadoras no processo educacional e na formação profissional e acadêmica (Barbosa; Junior; Mercado; Silva; Costa \& Nascimento, 2007) e seu uso em período pandêmico é praticamente indispensável. O setor educacional necessitou reinventarse frente às tecnologias de forma célere, as paredes das salas de aula desapareceram e surgiram computadores e smartphones para auxiliar na manutenção do ensino. Por isso, cabe salientar que:

[...] a tecnologia ocupou o local/espaço de encontros virtuais entre estudantes e professores, por meio da plataforma disponibilizada. Porém, cabe ressaltar que o uso de recursos tecnológicos não pode ser compreendido como simples repositório de materiais a que os alunos têm acesso na plataforma. Requer uma reformulação metodológica e curricular, já que é complexo e envolve, além de informações, a construção de conhecimentos, assumindo a subjetividade destes como aspecto relevante a ser considerado como um valor (Albuquerque, Gonçalves \& Bandeira, 2020, p. 109).

A partir dessa afirmação, não podemos considerar a mudança do ensino presencial para o remoto como uma mera substituição da lousa e canetas físicas para a utilização de artefatos tecnológicos. O momento atual exige reflexões sobre a prática pedagógica e adaptações para que o processo de ensino e aprendizagem ocorra de forma crítica e colaborativa. As TDIC podem contribuir de forma intensa na educação, uma vez que promovem mudanças em diversos âmbitos do meio educacional. Indagamos: como será a formação docente diante do uso das TDIC no período pós-pandemia?

\subsection{A formação de professores frente aos novos desafios}

O cenário educacional atual caracterizado pela pandemia COVID-19 exige novas posturas dos docentes, sendo imprescindível repensar as práticas educativas provenientes do distanciamento social causadas pelo fechamento de instituições de ensino no mundo inteiro. Essa situação desencadeou o que chamamos de Ensino Remoto Emergencial. Segundo Moreira e Schlemmer (2020, p. 07) a modalidade de ensino em questão, demandou que professores e alunos "migrassem para a realidade online, transferindo e transpondo metodologias e práticas pedagógicas típicas dos territórios físicos de aprendizagem".

Desta forma, a profissão docente passou a ser uma constante (re)construção, uma vez que, a sociedade está em constante transformação (Gatti, Sá Barreto, André, \& Almeida, 2019). Um dos desafios da educação é a inserção tecnológica e a problematização do uso de ferramentas digitais no ensino, que precisa ser feita principalmente pelos docentes através da reestruturação do trabalho pedagógico, explicado por Gatti et al. (2019, p. 19) como:

A essência das atividades escolares e, portanto, a essência do trabalho dos professores. Trabalho que, como em outros setores da atividade humana, precisa ser aprendido, e, para o qual já se consolidaram conhecimentos, onde a docência deixou de ser uma ação espontânea, que pode ser desenvolvida por intuições apenas, para se tornar campo de ação com base em fundamentos filosófico-sociais, histórico-psicológicos e fundamentos de práticas específicas que demandam domínio de conhecimentos integrados a conhecimentos científicos e humanistas para a ação educacional voltada às novas gerações, em que linguagens, tecnologias e estruturas interpretativas constituem seu cerne. 
Ao interagir e dialogar com o mundo e com a cultura digital, o professor reconstrói sua identidade profissional e elabora um saber tecnológico pertinente ao uso das tecnologias. Contudo, esse saber tecnológico passou a ser mais exigido dos educadores durante a pandemia, que não estavam preparados para lidar com as dificuldades emergentes, tais como barreiras no desenvolvimento das aulas remotas. Isso evidencia o baixo investimento educacional, bem como a falta de políticas efetivas de formação e valorização docente (Bezerra, Veloso \& Ribeiro, 2021, p. 3).

Os referidos autores sinalizam que a emergência da implementação das aulas remotas tornou-se um amplo desafio na educação, considerando pouca a abordagem sobre o uso de TDIC em espaços de formação de professores. Entretanto, Fürkotter e Morelatti (2008) argumentam que o professor deve ser capaz de integrar as novas tecnologias em sua prática docente. Para que isto ocorra, entendemos que são necessárias ações no contexto da formação de professores, tanto no âmbito da formação inicial como da formação continuada.

Nesta perspectiva, a formação inicial caracterizada como a obtenção de determinados princípios indispensáveis para a função e a atuação do futuro professor, terá que desempenhar uma formação mais sólida sobre o uso de metodologias de ensino com enfoque na tecnologia. A formação continuada de professores deverá permitir ao professor dar continuidade a aquisição de conhecimentos específicos de sua profissão, proporcionando mais cursos de aperfeiçoamento sobre o uso de ferramentas tecnológicas, para que o público docente sinta-se mais seguro e preparado para desenvolver o processo de ensino e aprendizagem na modalidade de ensino remoto.

\subsection{Tecnologias digitais como ferramentas pedagógicas}

Em decorrência da pandemia, o uso das tecnologias digitais se tornou uma alternativa para continuar a mediação do processo de ensino e aprendizagem remota. Deste quadro de transição, mudanças e adaptações reconfiguraram os meios de comunicação, resultando em novas maneiras de lidar com fontes e conteúdos midiáticos, que, por vezes, associam entretenimento e informação (Silva \& Behar, 2019).

Live streaming é uma tecnologia de transmissão ao vivo pela Web, a qual os participantes não precisam realizar o download instantâneo do conteúdo em áudio e/ou vídeo para assistir (Porto \& Santana, 2016). Os dados transmitidos por um computador, tablet ou smartphone podem ser recebidos em tempo real pelos usuários conectados ou também ser assistidos posteriormente, quando salvos. Grandes plataformas de conteúdo de entretenimento como Facebook, YouTube, Instagram, TikTok, entre outras, oferecem o recurso de forma gratuita para seus usuários realizarem a comunicação. Esse movimento foi catalisado pelo YouTube no ano de 2005, porém, apenas em 2011 esse recurso foi disponibilizado aos usuários (Netshow, 2017; Almeida \& Alves, 2020).

As transmissões em tempo real disseminam conteúdo envolvendo a participação de um grupo diversificado de pessoas distribuídas geograficamente pelo mundo, permitindo a interação instantânea entre os entrevistados e o público conectado, através do envio de mensagens no chat, comentários e curtidas no vídeo, uma vez que, todos são participantes ativos do encontro. Além disso, a redução dos custos na realização de um evento em formato online quando comparados ao presencial, o torna um parceiro em potencial aos usuários que não apresentam muitos recursos financeiros para investir em locomoção, alimentação e hospedagens para sua realização (Netshow, 2017).

Os encontros ao vivo pela Web reúnem pessoas de diferentes países em conteúdos de entretenimento como games, futebol, jornalismo, tutoriais e receitas de cozinha. Em um cenário de pandemia devido à COVID-19, no ano de 2020, esses mecanismos obtiveram maior notoriedade na área da educação, seja por meio da realização de webconferências, aulas e palestras (Almeida \& Alves, 2020).

Diante da realidade apresentada, os profissionais da área da educação precisaram buscar novas ferramentas para se conectar com seu público e aprender a dominar o computador, as ferramentas para realizar webconferências, os programas de 
codificação e os sites de transmissão para realizar tais atividades ao vivo. O desafio em propor e manter um ensino remoto qualificado exigiu dos profissionais o domínio de um conjunto de habilidades e competências específicas, com vistas ao desenvolvimento e aperfeiçoamento do letramento digital (Porto \& Santana, 2016).

$\mathrm{O}$ letramento digital pode ser entendido como "diferentes processos interligados e que representam a experiência e prática dos sujeitos em relação ao uso das tecnologias digitais" (Silva \& Behar, 2019, p. 22). O sujeito deve estar apto para acessar e utilizar os diferentes tipos de mídias, a fim de localizar e produzir informações eticamente, mobilizando um diálogo intercultural que amplie as competências digitais na sociedade.

Sendo assim, a realização de atividades na forma do ensino remoto demanda uma boa infraestrutura e investimento pessoal do criador de conteúdo, como uma internet de alta velocidade, computador, webcam, cenário e microfone, diferentemente da realização em um espaço escolar ou universitário, que geralmente possuem esses materiais e uma equipe dedicada à comunicação. Contudo, a existência de desigualdades presentes em todos os sistemas educacionais do Brasil sinaliza que o país apresenta uma realidade social e econômica heterogênea, sendo urgente o investimento em infraestruturas adequadas para acesso dessas ferramentas, capacitar os profissionais para seu uso e produzir materiais digitais inovadores e interativos (Almeida \& Alves, 2020).

\section{Encaminhamentos Metodológicos}

O projeto de extensão "Ciclos formativos de professores online: promoção de diálogos sobre educação" da UFSM foi organizado pela representação discente do PPGECQVS/UFSM, juntamente com doutora egressa do programa e Técnica de Biologia da UFSM, um professor do PPGECQV e contou com o auxílio de bolsista, mestranda do Programa de Pós-Graduação em Educação Matemática e Ensino de Física (PPGEMEF/UFSM). Os encontros ao vivo foram realizados em duas partes, na primeira os encontros não possuíam certificação, e na segunda fase foram produzidos três ciclos formativos, cada uma delas compostas por 12, 10 e 8 vídeos, respectivamente. Assim, para os participantes receberem a certificação, precisavam assistir dez encontros e responder aos questionários que continham uma pergunta sobre o assunto que foi abordado com no mínimo cinco linhas, além das informações como nome completo e e-mail para receber o certificado autenticado de 25 horas.

Os ciclos formativos ocorreram por meio da plataforma de vídeos YouTube, nomeado como Educação em Ciências UFSM1. Os encontros contaram com a participação de palestrantes tanto da UFSM quanto de outras instituições do país, com a mediação dos representantes da organização do projeto. O diálogo ocorreu por meio do chat - disponibilizado na própria plataforma - de modo que os participantes pudessem fazer questionamentos ao palestrante ou, ainda, dialogarem entre si.

As transmissões para o YouTube ocorreram através do uso streaming gratuito OBS Studio. Esse programa captura a tela do computador ou as janelas específicas, desse modo, foi adicionado a janela do Google Meet, a qual era realizado os encontros com os professores e demais profissionais para o diálogo. Entretanto, devido a praticidade e a demanda de processamento do computador com o uso do OBS Studio para realizar a codificação, foi emigrado as transmissões e encontros para o site Streamyard (https://streamyard.com/). Essa plataforma realiza a codificação e webconferência em sua versão gratuita ou paga, a fim de realizar o encontro incluindo até seis pessoas com áudio e webcam, que permitem o compartilhamento de tela para apresentação de imagens, vídeos e slides. No seu modo gratuito é possível realizar até 20 horas mensais de transmissão com a presença do logo do StreamYard no canto superior direito.

O público-alvo para desenvolvimento do projeto foram profissionais da educação, em especial, professores, atuantes na Educação Básica ou Ensino Superior, estudantes de pós-graduação, como também em formação inicial. Além disso, também participaram docentes internos e externos da UFSM e de outras instituições.

${ }^{1}$ Link de acesso disponível em: 〈https://www.youtube.com/channel/UCFH79rnc0qQcQu18zvLPIRQ>. 
Os temas para os ciclos formativos online foram escolhidos após o levantamento com os participantes das lives, bem como sugestões dos discentes do programa e organizados pela representação discente do programa Educação em Ciências da UFSM. Seguimos o protocolo de convidar os palestrantes e após o seu aceite verificar a disponibilidade do dia e hora para realização da live, repasse das orientações como o tempo de bate-papo, forma de funcionamento da plataforma de transmissão e a dinâmica de diálogo com o público.

Os palestrantes participantes dos diálogos online foram convidados de acordo com as suas linhas de pesquisas, produção, orientação e experiências relacionados com temas sugeridos pelos participantes ouvintes. Todos os convites ocorreram de forma voluntária e de acordo com o interesse do docente em colaborar com as reflexões e compartilhamento de ideias e experiências.

A organização dos ciclos formativos online ocorreu da seguinte forma: $\mathrm{O}(\mathrm{s})$ convidado(s) apresentava-se e realizava suas considerações a respeito do tema durante um tempo aproximado de 20 minutos. Em seguida, iniciava-se a primeira rodada de perguntas que eram enviadas via chat pelos participantes (em um período estimado de dez minutos). O mediador era responsável por apresentar as perguntas ao convidado. Após responder, o palestrante seguiu suas considerações por mais aproximadamente 20 minutos. Ao final de sua fala, o mediador, novamente, lançava as perguntas e comentários enviados. Durante a realização dos ciclos formativos online, os participantes do chat podiam trocar ideias, refletir e discutir o tema entre si. Assim, os ciclos formativos online tiveram a duração de aproximadamente uma hora.

A divulgação das lives foi realizada por meio de cards criados pela representação discente, os quais eram publicados com antecedência por e-mail e redes sociais. Assim, os ciclos formativos foram comunicados para outros Programas de PósGraduação em Educação em Ciências / Ensino em Ciências e Matemática do RS e outros estados do Brasil, com intuito de integrar mais profissionais da área. Foram também enviados convites via e-mail para secretarias de educação dos estados do RS e SC. Buscamos a participação de estudantes de cursos de Licenciatura e docentes que atuam nas escolas integradas a secretarias de educação do RS e SC, propiciando maior proximidade do alcance dos objetivos propostos no projeto, que visava alcançar a comunidade.

Neste trabalho iremos analisar e discutir alguns dados quantitativos sobre o desenvolvimento do projeto obtidos a partir da plataforma do YouTube, considerando o período de abril de 2020 a fevereiro de 2021. Além disso, foram analisados os temas abordados nas lives pelos palestrantes, assim como a sua formação inicial. Desse modo, as lives foram agrupadas conforme o assunto contemplado - dando origem aos temas. As formações iniciais dos palestrantes foram obtidas a partir da Plataforma Lattes.

\section{Resultados e Discussão}

\subsection{Caraterização do público participante}

Um dos principais resultados obtidos com o desenvolvimento do projeto foi o alcance e a quantidade de conteúdo produzido pelo canal, o qual foi se ampliando com o passar dos meses. Desse modo, destaca-se que o canal apresenta, atualmente, 3.804 inscritos, 44 vídeos produzidos ao vivo com mais de 80 horas de gravação, totalizando 12.700 horas exibidas. Foram recebidas 1.536 respostas e emitidos 75 certificados, ou seja, validadas 750 respostas as quais representam $48,82 \%$ dos participantes que cumpriram a regulamentação para certificação: assistir os vídeos (ao vivo ou não) e responderem pelo menos dez perguntas, podendo os demais participantes que não concluíram as respostas pertencentes ao primeiro ciclo assistir e responder os formulários do segundo e/ou terceiro ciclo.

Os 75 atestados foram divididos em 53, no primeiro, 17, no segundo, 5, no terceiro ciclo. A queda dos números, possivelmente ocorreu em decorrência da diminuição de visualizações durante os encontros ao vivo. Com o passar dos meses da pandemia, as universidades, escolas e empresas retornaram às suas atividades de modo presencial, remota ou híbrida e com 
isso trouxe uma saturação no grande número de lives produzidas sobre assuntos diversificados pelo Brasil e no mundo. Possivelmente, isso fez com que os indivíduos ficassem mais ocupados e, consequentemente, levando a um maior cansaço mental e emocional causado pelo período da pandemia.

Em relação a caracterização do público participante dos ciclos formativos, foram analisados o gênero, idade e dispositivos de acesso às lives, esses dados representam os participantes inscritos e não inscritos no canal. Além disso, identificamos as regiões brasileiras e país dos palestrantes, bem como as suas formações iniciais e os temas abordados nas lives.

Em relação a caracterização dos sujeitos quanto ao gênero, percebemos que a maioria do público participante eram mulheres, sendo representadas por um percentual de $75,3 \%$. Já o público masculino representou um total de $24,7 \%$ dos participantes, conforme pode ser observado na Figura 1.

Figura 1. Gráfico da caracterização do público inscrito e não inscrito do canal quanto ao gênero dos sujeitos.

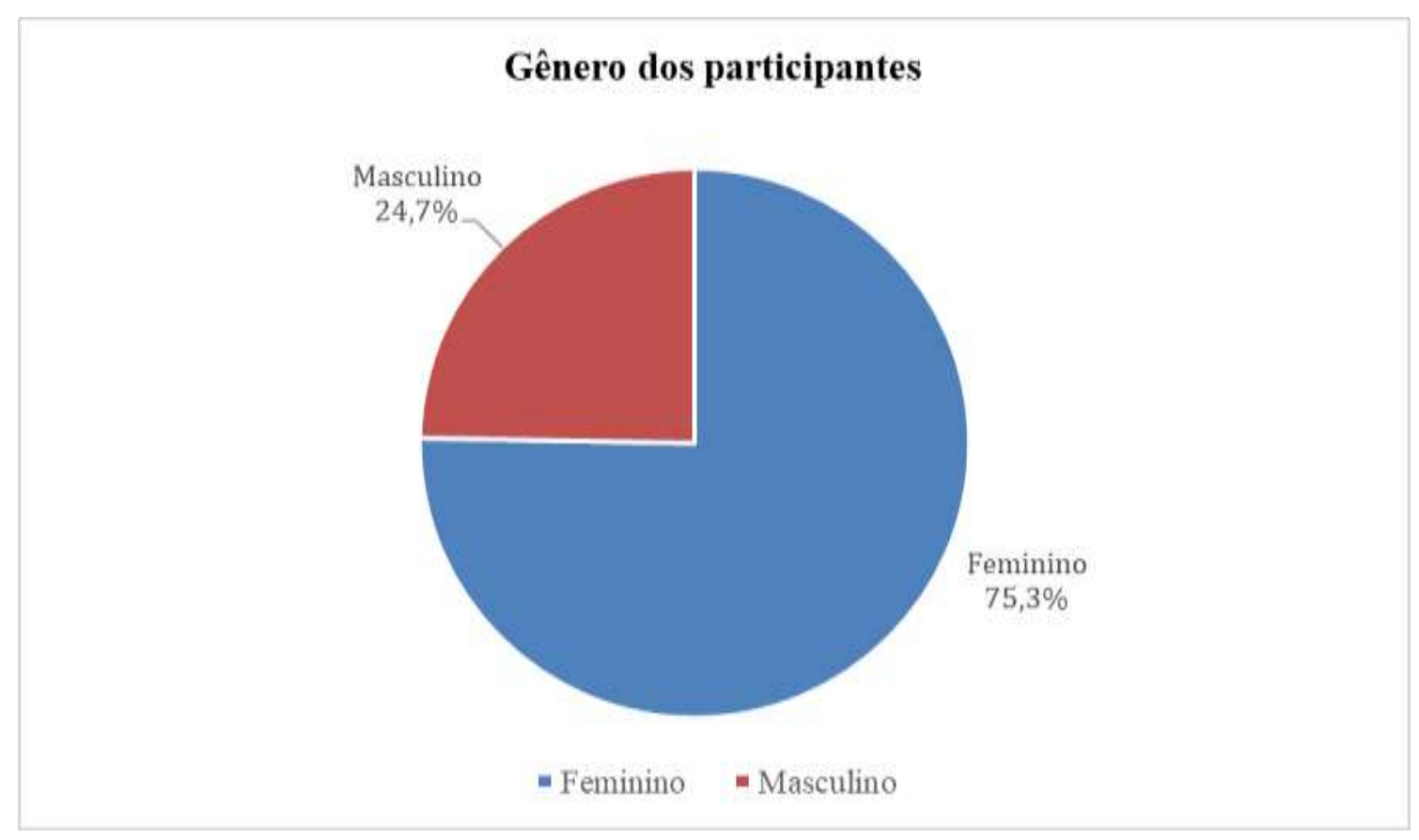

Fonte: Autores (2021).

De acordo com Leta (2003) a expansão da comunidade científica na história do Brasil é recente e embora historicamente a ciência seja atribuída a uma atividade realizada por homens, a participação das mulheres na ciência nos anos 80 e 90 aumentou no setor. A autora pontua que hoje as mulheres são maioria em boa parte dos cursos de graduação e pósgraduação. Entretanto, no estudo de Barreto (2014) é apontado que ainda há cursos que são mais femininos, como aqueles relacionados ao cuidado e à educação e cursos mais masculinos como os ligados à área de tecnologias e engenharias. Neste sentido, de acordo com o Censo da Educação Superior (MEC, 2020), 72,2 \% dos alunos matriculados em cursos de graduação em licenciatura é feminino. Tal dado corrobora com a expressividade feminina observada como o público participante do projeto.

Outro dado refere-se às faixas etárias do público participante, isto é, o público era muito diverso em relação a idade. A Figura 2 refere-se a um gráfico que apresenta as diferentes idades do público inscrito e não inscrito no canal do YouTube. Conforme pode ser visualizado há um percentual expressivo de participantes com idades entre 25 e 34 anos, assim como dos 35 aos 44 anos. 
Figura 2. Gráfico da caracterização do público inscrito no canal quanto a idade dos sujeitos.

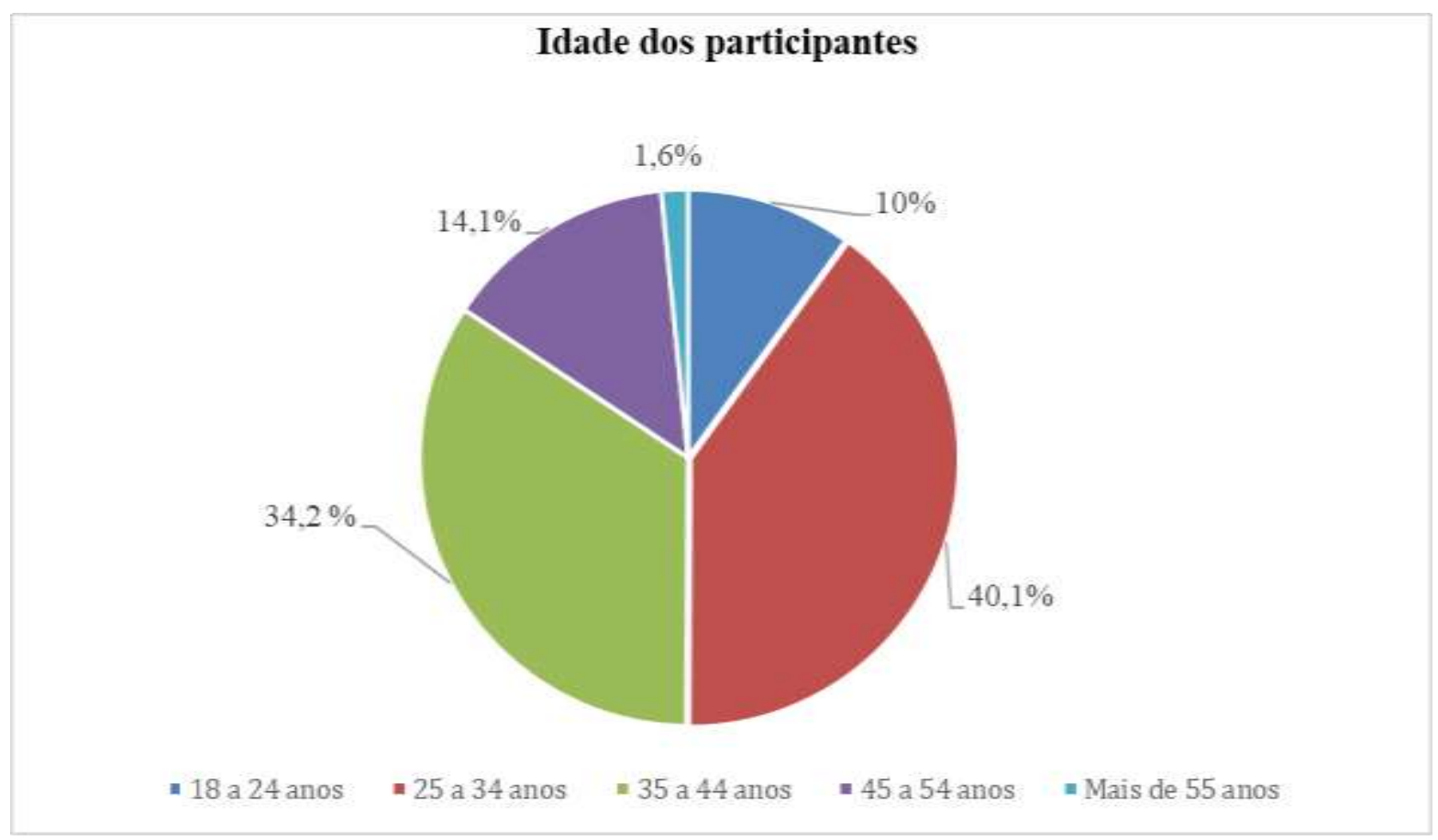

Fonte: Autores (2021).

Em relação aos dispositivos utilizados pelo público participante para acesso às lives, identificamos uma predominância do uso de dispositivos móveis, isto é, principalmente, celulares, totalizando um percentual de 53,8 \%. Todavia, também houve uma presença bastante significativa de computadores com um total de 43,5\%, além disso, também foram utilizadas TVs $(2,6 \%)$ e consolo de jogos $(0,1 \%)$. Esses percentuais podem ser visualizados na Figura 3:

Figura 3. Gráfico do dispositivo utilizado para acesso às lives dos ciclos formativos.

\section{Tipo de dispositivo utilizado para o acesso}

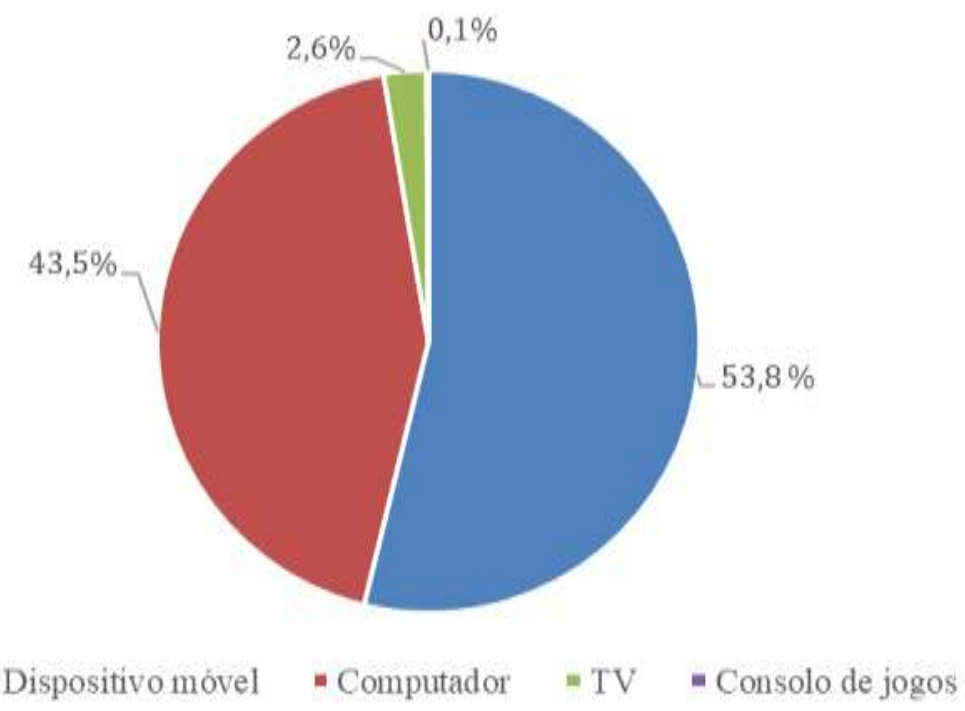

Fonte: Autores (2021). 
Os dados demonstram a utilização expressiva de aparelhos de dispositivos móveis como exemplo de TDIC muito utilizado pelo público do canal. De acordo com uma notícia publicada na Mobile Time (2020) com a pandemia aumentou-se o uso de smartphones. $\mathrm{O}$ uso de celulares para acesso aos vídeos do canal pode ser uma forma rápida de acesso e que pode ser feita de qualquer local desde que tenha acesso a internet.

\subsection{Caracterização dos palestrantes}

O projeto contou com a participação de 58 palestrantes, sendo estes pertencentes a todas as regiões brasileiras, além de um residente no exterior (Portugal). Conforme pode ser visualizado no mapa (Figura 4), a região Sul e Sudeste foram as que mais tiveram participação de palestrantes, com 33 e 15 palestrantes, respectivamente. Isso pode ser justificado pelo fato de que a instituição responsável pelo projeto está localizada na região Sul do país. Já a região brasileira com menor participação foi a região Centro-Oeste, com apenas um palestrante, conforme pode ser conferido no gráfico.

Além da região em que os palestrantes residem/trabalham, foi realizada uma análise de suas formações iniciais (Figura 5). Ressaltamos que para a análise consideramos todas as graduações dos palestrantes, ademais, para a elaboração do gráfico não se fez distinção entre os cursos de licenciatura e bacharelado, ou seja, para os palestrantes que possuíam tanto licenciatura quanto bacharelado no mesmo curso foram contabilizados uma única vez, conforme pode ser visto na Figura 5 abaixo:

Figura 4. Caracterização dos palestrantes quanto às regiões brasileiras.

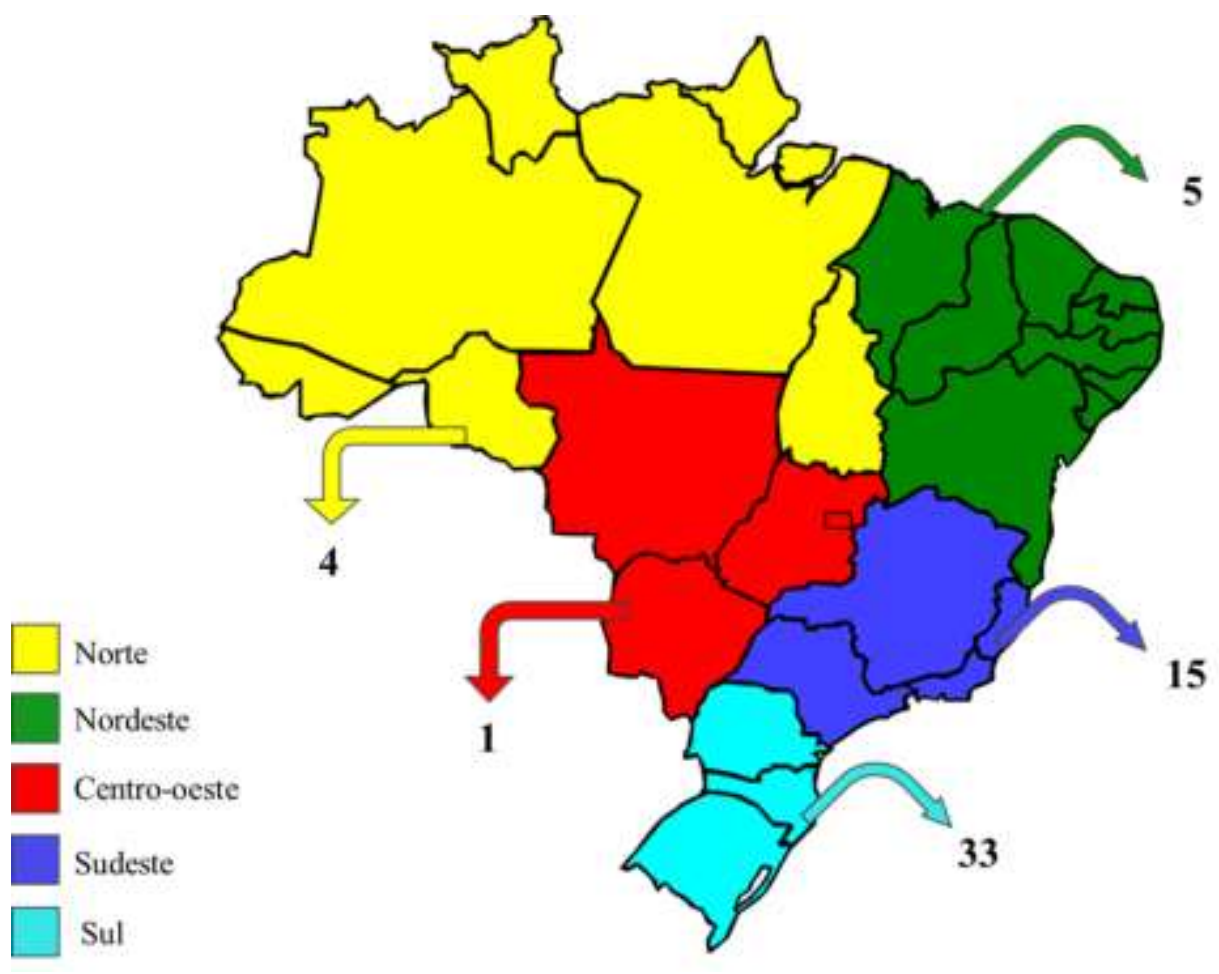

Fonte: Autores (2021). 
Figura 5. Gráfico de caracterização dos palestrantes quanto aos seus cursos de formação inicial.

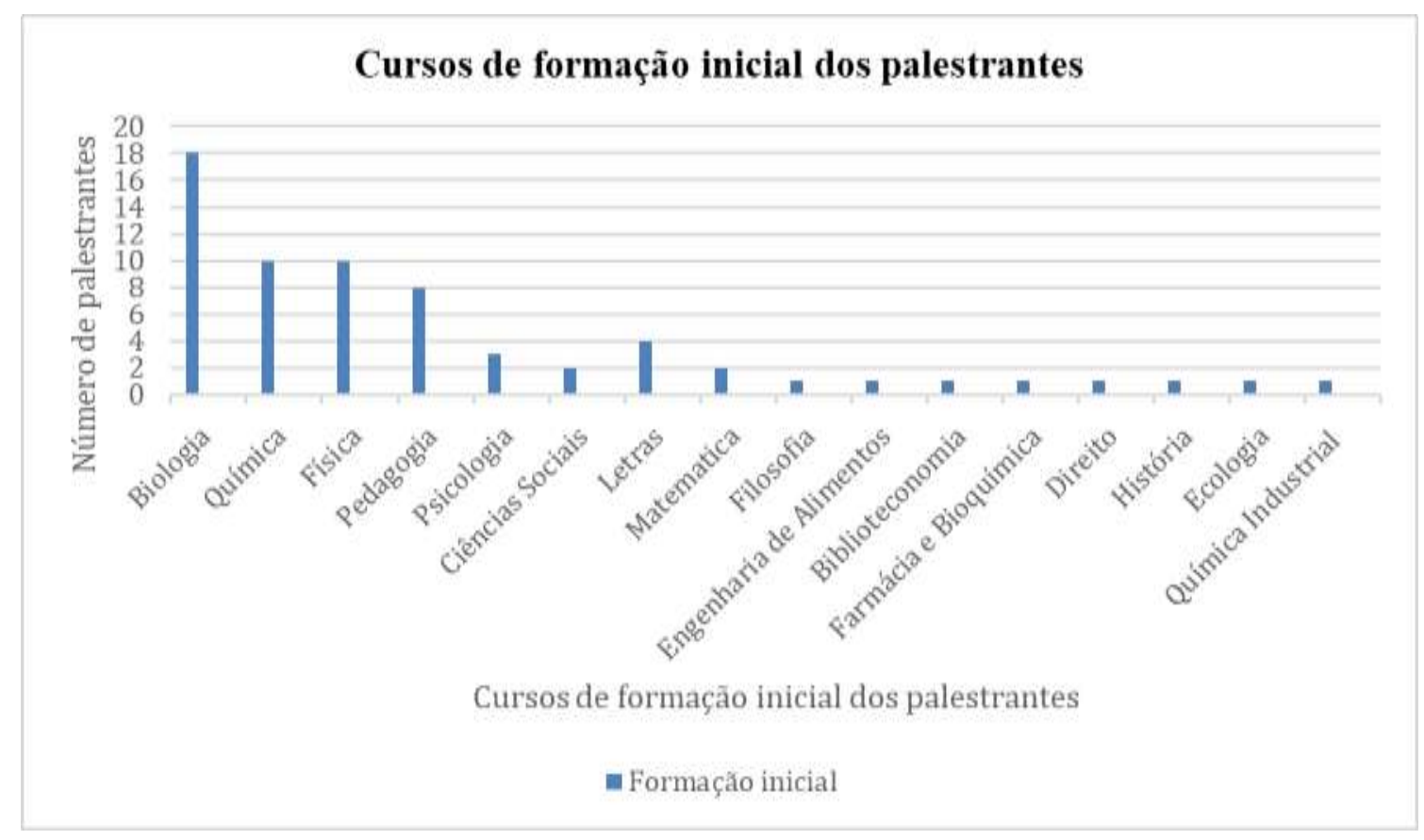

Fonte: Autores (2021).

Percebemos uma expressiva participação de profissionais formados no curso de Biologia, sendo representados por 19 palestrantes. Além disso, em segunda posição houve predominância de profissionais com formação em Química e Física, com uma representação de dez palestrantes em cada um dos cursos. Destacamos que a presença desses profissionais se dá em função do canal ser originado de um programa da área de Educação em Ciências. Todavia, ressaltamos a diversidade de profissionais participantes das lives, não ficando restrito somente a área de Educação em Ciências (Quadro 1).

Quadro 1. Informações das lives realizadas.

\begin{tabular}{|c|c|c|c|}
\hline Título da live & Palestrante & Formação inicial & Atuação profissional \\
\hline $\begin{array}{l}1^{\text {a }} \text { Educação para alavancar a } \\
\text { curva da Ciência }\end{array}$ & $\begin{array}{l}\text { Dr. Luiz Caldeira Brant de } \\
\text { Tolentino Neto }\end{array}$ & $\begin{array}{l}\text { Bacharelado e Licenciatura em } \\
\text { Ciências Biológicas }\end{array}$ & $\begin{array}{l}\text { Universidade Federal de Santa } \\
\text { Maria - RS }\end{array}$ \\
\hline $2^{\mathrm{a}}$ Metodologias ativas & $\begin{array}{l}\text { Me. Rodrigo Venturoso Mendes } \\
\text { da Silveira }\end{array}$ & $\begin{array}{l}\text { Bacharelado e Licenciatura em } \\
\text { Ciências Biológicas }\end{array}$ & Colégio Móbile - SP \\
\hline $3^{\circ}$ TEA e inclusão & $\begin{array}{l}\text { Dra. Gisele Soares Lemos Shaw } \\
\text { Dra. Kaline Jurema Jambeiro } \\
\text { Rocha }\end{array}$ & $\begin{array}{l}\text { Licenciatura em Pedagogia } \\
\text { Psicologia }\end{array}$ & $\begin{array}{l}\text { Universidade Federal do Vale do } \\
\text { São Francisco - BA } \\
\text { Espaço multidisciplinar Aceitar } \\
\text { Estimular e Incluir -BA }\end{array}$ \\
\hline $\begin{array}{l}4^{\circ} \text { Educação em Ciências e } \\
\text { integração das TIC em tempos de } \\
\text { pandemia }\end{array}$ & $\begin{array}{l}\text { Dr. Dioni Paulo Pastorio } \\
\text { Dr. Muryel Pyetro Vidmar } \\
\text { Dr. André Ary Leonel }\end{array}$ & $\begin{array}{l}\text { Licenciatura em Física } \\
\text { Licenciatura em Física } \\
\text { Licenciatura em Física }\end{array}$ & $\begin{array}{l}\text { Universidade Federal do Rio } \\
\text { Grande do Sul - RS } \\
\text { Universidade Federal de Santa } \\
\text { Maria - RS } \\
\text { Universidade Federal de Santa } \\
\text { Catarina - SC }\end{array}$ \\
\hline
\end{tabular}




\begin{tabular}{|c|c|c|c|}
\hline $\begin{array}{l}5^{\circ} \text { Educação } 4.0 \text { e os desafios da } \\
\text { docência }\end{array}$ & Dra. Rosangela Silveira Garcia & $\begin{array}{l}\text { Licenciatura em Letras } \\
\text { Português e em Pedagogia }\end{array}$ & Contextual Formação Docente - RS \\
\hline $\begin{array}{l}6^{\circ} \text { Metodologias ativas e } \\
\text { abordagem investigativa: desafios } \\
\text { e possibilidades }\end{array}$ & $\begin{array}{l}\text { Me. Gracieli Dall Ostro Persich } \\
\text { Dra Luciana Maria de Jesus } \\
\text { Baptista Gomes }\end{array}$ & $\begin{array}{l}\text { Licenciatura em Pedagogia e } \\
\text { Bacharelado e licenciada em } \\
\text { Ciência Biológicas } \\
\text { Licenciatura em Ciência } \\
\text { Biológicas }\end{array}$ & $\begin{array}{l}\text { Colégio Tiradentes da Brigada } \\
\text { Militar - RS } \\
\text { Faculdade Santo Ângelo - RS } \\
\text { Secretaria Estadual de Educação do } \\
\text { Rio De Janeiro - RJ }\end{array}$ \\
\hline $\begin{array}{l}7^{\circ} \text { Análise Textual Discursiva: } \\
\text { entre a descrição e a compreensão }\end{array}$ & Dra Maria do Carmo Galiazzi & $\begin{array}{l}\text { Bacharelado em Química e } \\
\text { Licenciatura em Ciências com } \\
\text { Habilitação em Química }\end{array}$ & $\begin{array}{l}\text { Universidade Federal do Rio } \\
\text { Grande - RS }\end{array}$ \\
\hline $\begin{array}{l}8^{\circ} \text { A docência compartilhada } \\
\text { como estratégia para o ensino de } \\
\text { ciências: planejamento, ação e } \\
\text { vivências. }\end{array}$ & $\begin{array}{l}\text { Me. Gian Giermanowicz Costa } \\
\text { Dra. Lisandra Catalan do Amaral } \\
\text { Dra. Manoela Argenton Prado }\end{array}$ & $\begin{array}{l}\text { Licenciatura em Ciências } \\
\text { Biológicas } \\
\text { Licenciatura e Bacharelado em } \\
\text { Química } \\
\text { Bacharelado em Química } \\
\text { Industrial e Química } \\
\text { Licenciatura }\end{array}$ & $\begin{array}{l}\text { Colégio Marista Rosário-RS } \\
\text { Rede Marista- RS } \\
\text { Pontifícia Universidade Católica do } \\
\text { Rio Grande do Sul-RS } \\
\text { Colégio Marista São Pedro e } \\
\text { Colégio Marista Rosário-RS }\end{array}$ \\
\hline $\begin{array}{l}9^{\circ} \text { Narrativas de formação em } \\
\text { Ciências: investigação, formação } \\
\text { e ação (no desenvolvimento } \\
\text { profissional docente) }\end{array}$ & $\begin{array}{l}\text { Dr. Roque Ismael da Costa } \\
\text { Gullich }\end{array}$ & $\begin{array}{l}\text { Licenciatura em Ciências } \\
\text { Biológicas e Formação de } \\
\text { professores de Disciplinas } \\
\text { Especializadas }\end{array}$ & $\begin{array}{l}\text { Universidade Federal da Fronteira } \\
\text { Sul -RS }\end{array}$ \\
\hline $\begin{array}{l}10^{\circ} \text { Conversando sobre CTS, } \\
\text { CTSA, PLACTS e, também, } \\
\text { sobre coronavírus }\end{array}$ & Dr. Décio Auler & Licenciatura em Física & $\begin{array}{l}\text { Universidade Federal de Santa } \\
\text { Maria - RS }\end{array}$ \\
\hline $\begin{array}{l}11^{\circ} \text { Confabulações acerca da } \\
\text { Alfabetização científica }\end{array}$ & Dr. Attico Chassot & Licenciatura em Química & $\begin{array}{l}\text { Universidade Federal do Sul e } \\
\text { Sudeste do Pará - PA }\end{array}$ \\
\hline $12^{\circ}$ (DES)Construindo o gênero & $\begin{array}{l}\text { Dra. Liliana Souza de Oliveira } \\
\text { Gabriella Meindrad Santos de } \\
\text { Souza }\end{array}$ & $\begin{array}{l}\text { Licenciatura em Filosofia } \\
\text { Graduanda em Direito }\end{array}$ & $\begin{array}{l}\text { Instituto Federal Farroupilha - RS } \\
\text { Servidora Pública. Secretária } \\
\text { Adjunta de Estado da Cultura RS. } \\
\text { Diretora-Geral da Secretaria de } \\
\text { Estado da Cultura do Rio Grande do } \\
\text { Sul - Sedac RS }\end{array}$ \\
\hline $\begin{array}{l}13^{\circ} \text { Ferramentas Colaborativas no } \\
\text { apoio ao ensino Remoto }\end{array}$ & $\begin{array}{l}\text { Me: Carlos Gustavo Lopes da } \\
\text { Silva } \\
\text { Dr. Márcio Marques Martins }\end{array}$ & $\begin{array}{l}\text { Licenciatura em Pedagogia, } \\
\text { graduação em Programas } \\
\text { Especiais Formação de } \\
\text { Professores e Bacharelado em } \\
\text { Farmácia Bioquímica } \\
\\
\text { Licenciatura e Bacharelado em } \\
\text { Química }\end{array}$ & $\begin{array}{l}\text { Professor Conteudista UFSM, } \\
\text { MUST University, SAGAH } \\
\text { Soluções Educacionais, DELINEA, } \\
\text { Faculdades Marcelinas EAD, } \\
\text { DTCOM e OPEN } \\
\text { EDUCACIONAL. } \\
\text { Universidade Federal do Pampa - } \\
\text { RS }\end{array}$ \\
\hline $14^{\circ}$ Ensino de Ciências na EJA & Dr. Felipe Bandoni de Oliveira & $\begin{array}{l}\text { Licenciatura e Bacharelado em } \\
\text { Ciência Biológicas }\end{array}$ & Colégio Santa Cruz- SP \\
\hline $\begin{array}{l}15^{\circ} \text { Os impactos da pandemia na } \\
\text { sala de aula: o desafio do docente } \\
\text { em transformar as metodologias } \\
\text { ativas em práticas remotas }\end{array}$ & Dra. Janaína Pretto Carlesso & Psicologia & Universidade Franciscana - RS \\
\hline
\end{tabular}




\begin{tabular}{|c|c|c|c|}
\hline $\begin{array}{l}16^{\circ} \text { Análise de dados qualitativos: } \\
\text { explorando as possibilidades } \\
\text { através da Teoria Fundamentada }\end{array}$ & Dr. Cirlande Cabral da Silva & $\begin{array}{l}\text { Licenciatura em Ciências } \\
\text { Biológicas }\end{array}$ & $\begin{array}{l}\text { Instituto Federal de Educação, } \\
\text { Ciência e Tecnologia do Amazonas- } \\
\text { AM }\end{array}$ \\
\hline $\begin{array}{l}17^{\circ} \text { Parte II: Análise Textual } \\
\text { Discursiva: Das perguntas ao } \\
\text { metatexto }\end{array}$ & Dra Maria do Carmo Galiazzi & $\begin{array}{l}\text { Bacharelado em Química e } \\
\text { licenciatura em Ciências com } \\
\text { Habilitação em Química }\end{array}$ & $\begin{array}{l}\text { Universidade Federal do Rio } \\
\text { Grande - RS }\end{array}$ \\
\hline $\begin{array}{l}18^{\circ} \text { Por que será que "furamos" o } \\
\text { isolamento social? Reflexões } \\
\text { sobre a Educação em Saúde }\end{array}$ & Dr. Julio Cesar Bresolin Marinho & $\begin{array}{l}\text { Licenciatura Ciências } \\
\text { Biológicas }\end{array}$ & $\begin{array}{l}\text { Universidade Federal do Pampa - } \\
\text { RS }\end{array}$ \\
\hline $\begin{array}{l}19^{\circ} \text { A relevância de Freire, } \\
\text { Educação Popular e os cursinhos } \\
\text { populares na atualidade }\end{array}$ & Dr. Thiago Ingrassia Pereira & $\begin{array}{l}\text { Licenciatura e Bacharelado em } \\
\text { Ciências Sociais }\end{array}$ & $\begin{array}{l}\text { Universidade Federal da Fronteira } \\
\text { Sul - RS }\end{array}$ \\
\hline $\begin{array}{l}20^{\circ} \text { Avaliação da aprendizagem } \\
\text { escolar }\end{array}$ & Dr. Wagner Bandeira & Psicologia & Universidade Federal do Ceará - CE \\
\hline $21^{\circ}$ Teatro na escola & Bernadete Lovato & Letras & Colégio Marista Roque- RS \\
\hline $\begin{array}{l}22^{\circ} \text { Artigo científico: passos para } \\
\text { a produção e publicação }\end{array}$ & $\begin{array}{l}\text { Dr. Luiz Caldeira Brant de } \\
\text { Tolentino Neto } \\
\text { Dra. Jaiane de Moraes Boton } \\
\text { Me.José Francisco Zavaglia } \\
\text { Marques }\end{array}$ & $\begin{array}{l}\text { Bacharelado e Licenciatura em } \\
\text { Ciências Biológicas } \\
\text { Licenciatura em Ciências } \\
\text { Biológicas } \\
\text { Licenciatura em Química }\end{array}$ & $\begin{array}{l}\text { Universidade Federal de Santa } \\
\text { Maria - RS } \\
\text { Escola Medianeira - RS } \\
\text { Colégio Marista Santa Maria- RS }\end{array}$ \\
\hline $\begin{array}{l}23^{\circ} \text { Atividades Experimentais } \\
\text { Problematizadoras }\end{array}$ & Dr. André Luís Silva da Silva & Licenciatura em Química & $\begin{array}{l}\text { Universidade Federal do Pampa - } \\
\text { RS }\end{array}$ \\
\hline $\begin{array}{l}24^{\circ} \text { Procure a Biblioteca da sua } \\
\text { Instituição: contributo das Fontes } \\
\text { de Informação, Citações e } \\
\text { Referências para as Pesquisas } \\
\text { Científicas. }\end{array}$ & Me: Deisiré Amaral Lobo & Biblioteconomia & $\begin{array}{l}\text { Universidade Federal de Santa } \\
\text { Maria - RS }\end{array}$ \\
\hline $\begin{array}{l}25^{\circ} \text { Iniciação científica na } \\
\text { Educação Básica: desafios e } \\
\text { experiências }\end{array}$ & $\begin{array}{l}\text { Dra. Flávia Santos Twardowski } \\
\text { Pinto } \\
\text { Me. Cláudius Jardel Soares }\end{array}$ & $\begin{array}{l}\text { Bacharelado em Engenharia de } \\
\text { Alimentos } \\
\text { Licenciatura em Ciências e e } \\
\text { em Química }\end{array}$ & $\begin{array}{l}\text { Instituto Federal de Educação, } \\
\text { Ciência e Tecnologia do Rio } \\
\text { Grande do Sul - RS } \\
\text { Instituto Federal de Educação, } \\
\text { Ciência e Tecnologia do Rio } \\
\text { Grande do Sul - RS }\end{array}$ \\
\hline $\begin{array}{l}26^{\circ} \text { Currículo na perspectiva } \\
\text { freireana }\end{array}$ & $\begin{array}{l}\text { Dr. Antonio Fernando Gouvêa da } \\
\text { Silva }\end{array}$ & $\begin{array}{l}\text { Licenciatura e Bacharelado em } \\
\text { Biologia }\end{array}$ & $\begin{array}{l}\text { Universidade Federal de São Carlos } \\
\text { - SP }\end{array}$ \\
\hline $\begin{array}{l}27^{\circ} \text { O estágio supervisionado } \\
\text { como espaço de construção da } \\
\text { identidade docente }\end{array}$ & $\begin{array}{l}\text { Dr. Victor Hugo Paes de } \\
\text { Magalhães dos Santos }\end{array}$ & Licenciatura em Química & $\begin{array}{l}\text { Instituto Federal de } \\
\text { Educação,Ciência e Tecnologia do } \\
\text { Rio de Janeiro - RJ }\end{array}$ \\
\hline $\begin{array}{l}28^{\circ} \text { Práticas Docentes para os } \\
\text { novos tempos. }\end{array}$ & $\begin{array}{l}\text { Dra. Maria Regina Dubeux } \\
\text { Kawamura } \\
\text { Dra. Inés Prieto Schmidt } \\
\text { Sauerwein }\end{array}$ & $\begin{array}{l}\text { Bacharelado em Física } \\
\text { Licenciatura em Física }\end{array}$ & $\begin{array}{l}\text { Universidade de São Paulo - SP } \\
\text { Universidade Federal de Santa } \\
\text { Maria - RS }\end{array}$ \\
\hline $\begin{array}{l}29^{\circ} \text { Movimento CTS: estudos, } \\
\text { pesquisas e reflexões }\end{array}$ & $\begin{array}{l}\text { Dr. Paulo Marcelo Marini } \\
\text { Teixeira }\end{array}$ & $\begin{array}{l}\text { Licenciatura em Ciências } \\
\text { Habilitação em Biologia e } \\
\text { Licenciatura em Matemática }\end{array}$ & $\begin{array}{l}\text { Universidade Estadual do Sudoeste } \\
\text { da Bahia - BA }\end{array}$ \\
\hline
\end{tabular}




\begin{tabular}{|c|c|c|c|}
\hline $\begin{array}{l}30^{\circ} \text { A práxis pedagógica autêntica } \\
\text { em Freire }\end{array}$ & $\begin{array}{l}\text { Dr. Antonio Fernando Gouvêa da } \\
\text { Silva }\end{array}$ & $\begin{array}{l}\text { Licenciatura e Bacharelado em } \\
\text { Biologia }\end{array}$ & $\begin{array}{l}\text { Universidade Federal de São Carlos } \\
\text { - SP }\end{array}$ \\
\hline $\begin{array}{l}31^{\circ} \text { Tensões do futuro: denunciar } \\
\text { e enunciar em educação }\end{array}$ & $\begin{array}{l}\text { Dr. Vantoir Roberto Brancher } \\
\text { Dra. Maria Isabel da Cunha } \\
\text { Dra. Valeska Maria Fortes de } \\
\text { Oliveira }\end{array}$ & $\begin{array}{l}\text { Licenciatura em Pedagogia } \\
\text { Licenciatura em Ciências } \\
\text { Sociais e em Pedagogia } \\
\text { Licenciatura em Pedagogia }\end{array}$ & $\begin{array}{l}\text { Instituto Federal de Educação } \\
\text { Ciência e Tecnologia Farroupilha - } \\
\text { RS } \\
\text { Universidade Federal de Pelotas - } \\
\text { RS } \\
\text { Universidade Federal de Santa } \\
\text { Maria - RS }\end{array}$ \\
\hline $\begin{array}{l}32^{\circ} \text { Divulgação Científica e o } \\
\text { Show da Luna. }\end{array}$ & $\begin{array}{l}\text { Suzana Facchini Granato } \\
\text { Francisco Mistrorigo }\end{array}$ & $\begin{array}{l}\text { Licenciatura em Ciências } \\
\text { Biológicas } \\
\text { Arquitetura e Urbanismo }\end{array}$ & $\begin{array}{l}\text { Clínica de Psicologia KN - SP } \\
\text { Tv PinGuim-SP }\end{array}$ \\
\hline $\begin{array}{l}33^{\circ} \text { Música e matemática: } \\
\text { relações que favorecem a } \\
\text { aprendizagem }\end{array}$ & Me. Fernando Moreira Barnabé & Licenciatura em Matemática & $\begin{array}{l}\text { Professor, palestrante, autor e editor } \\
\text { de livros didáticos. }\end{array}$ \\
\hline $\begin{array}{l}34^{\circ} \text { Divulgação Científica e Feira } \\
\text { de Ciências }\end{array}$ & Dr. Ivo Leite Filho & Licenciatura em Química & $\begin{array}{l}\text { Universidade Federal de Mato } \\
\text { Grosso do Sul - MS }\end{array}$ \\
\hline $\begin{array}{l}35^{\circ} \text { O que os professores pensam } \\
\text { quando ensinam conteúdos } \\
\text { metacientíficos? }\end{array}$ & $\begin{array}{l}\text { Dr. Boniek Venceslau da Cruz } \\
\text { Silva }\end{array}$ & Licenciatura em Física & Universidade Federal do Piauí - PI \\
\hline $36^{\circ}$ Educação Ambiental & Dr. Carlos Frederico Loureiro & $\begin{array}{l}\text { Licenciatura em Ciências } \\
\text { Físicas e Biológicas e Ecologia }\end{array}$ & $\begin{array}{l}\text { Universidade Federal do Rio de } \\
\text { Janeiro - RJ }\end{array}$ \\
\hline $\begin{array}{l}37^{\circ} \text { STEAM na prática: uma } \\
\text { possibilidade de transformação do } \\
\text { ensino de Ciências }\end{array}$ & $\begin{array}{l}\text { Dra. Mariana Peão Lorenzin } \\
\text { Renato Pacheco Villar }\end{array}$ & $\begin{array}{l}\text { Licenciatura e Bacharelado em } \\
\text { Ciências Biológicas } \\
\text { Bacharelado e Licenciatura em } \\
\text { Física }\end{array}$ & $\begin{array}{l}\text { Colégio Bandeirantes - SP } \\
\text { Colégio Bandeirantes - SP }\end{array}$ \\
\hline $\begin{array}{l}38^{\circ} \text { Situação de Estudo e } \\
\text { Organização Curricular }\end{array}$ & $\begin{array}{l}\text { Dr. Milton Antonio Auth } \\
\text { Dra. Maria Cristina Pansera de } \\
\text { Araújo }\end{array}$ & $\begin{array}{l}\text { Licenciatura em Física } \\
\text { Licenciatura em Ciências } \\
\text { Biológicas }\end{array}$ & $\begin{array}{l}\text { Universidade Federal de Uberlândia } \\
\text {-MG } \\
\text { Universidade Regional do Noroeste } \\
\text { do Estado do Rio Grande do Sul - } \\
\text { RS }\end{array}$ \\
\hline $\begin{array}{l}39^{\circ} \text { Educação ambiental: } \\
\text { participação ativa dos sujeitos na } \\
\text { transformação da sua realidade }\end{array}$ & Dr. Carlos Frederico Loureiro & $\begin{array}{l}\text { Licenciatura em Ciências } \\
\text { Físicas e Biológicas e Ecologia }\end{array}$ & $\begin{array}{l}\text { Universidade Federal do Rio de } \\
\text { Janeiro - RJ }\end{array}$ \\
\hline $\begin{array}{l}40^{\circ} \text { Por entre quereres e fazeres } \\
\text { da educação ambiental: reflexões } \\
\text { emergentes acerca da práxis } \\
\text { pedagógica }\end{array}$ & $\begin{array}{l}\text { Dra. Mônica Andrade Modesto } \\
\text { Dra. Aline Lima de Oliveira } \\
\text { Nepomuceno }\end{array}$ & $\begin{array}{l}\text { Licenciatura em Pedagogia } \\
\text { Licenciatura em Ciências } \\
\text { Biológicas }\end{array}$ & $\begin{array}{l}\text { Universidade Federal de Sergipe - } \\
\text { SE } \\
\text { Universidade Federal de Sergipe - } \\
\text { SE }\end{array}$ \\
\hline $\begin{array}{l}41^{\circ} \text { Investigação sobre formação } \\
\text { docente }\end{array}$ & $\begin{array}{l}\text { Dra. Maria Manuela Franco } \\
\text { Esteves }\end{array}$ & Licenciatura em História & $\begin{array}{l}\text { Instituto de Educação - Escola da } \\
\text { Universidade de Lisboa - Portugual }\end{array}$ \\
\hline $\begin{array}{l}42^{\circ} \text { Museus e Centros de Ciências } \\
\text { - práticas e pesquisas }\end{array}$ & Dra. Jessica Norberto Rocha & Licenciatura em Letras & $\begin{array}{l}\text { Fundação Centro de Ciências e de } \\
\text { Educação Superior a Distância do } \\
\text { Estado do Rio de Janeiro -RJ }\end{array}$ \\
\hline
\end{tabular}




\begin{tabular}{|l|l|l|l|}
\hline $\begin{array}{l}43^{\circ} \text { Bourdieu e o Ensino de } \\
\text { Ciências: contribuições para a } \\
\text { questão da desigualdade social e } \\
\text { educacional }\end{array}$ & Dra. Graciella Watanabe & Licenciatura em Física & $\begin{array}{l}\text { Fundação Universidade Federal do } \\
\text { ABC - SP }\end{array}$ \\
\hline $\begin{array}{l}44^{\circ} \text { Educação Científica e } \\
\text { Formação de Professores de } \\
\begin{array}{l}\text { Ciências em Espaços de } \\
\text { Educação Não Formal }\end{array}\end{array}$ & $\begin{array}{l}\text { Dra. Sinaida Maria Vasconcelos } \\
\text { Dra. Bianca Venturieri }\end{array}$ & $\begin{array}{l}\text { Licenciatura em Ciências } \\
\text { Biológicas } \\
\text { Licenciatura em Ciências } \\
\text { Biológicas }\end{array}$ & $\begin{array}{l}\text { Universidade do Estado do Pará - } \\
\text { Universidade do Estado do Pará - } \\
\text { PA }\end{array}$ \\
\hline
\end{tabular}

Fonte: Autores (2021).

Ademais, salienta-se que foi realizada uma análise dos temas contemplados pelas lives, desse modo, as lives foram agrupadas considerando o assunto abordado em cada uma delas. Então, das 44 lives identificou-se pelo menos 17 temas diferentes, os quais estão presentes no gráfico abaixo (Figura 6).

Figura 6. Gráfico com os temas abordados durante as lives.

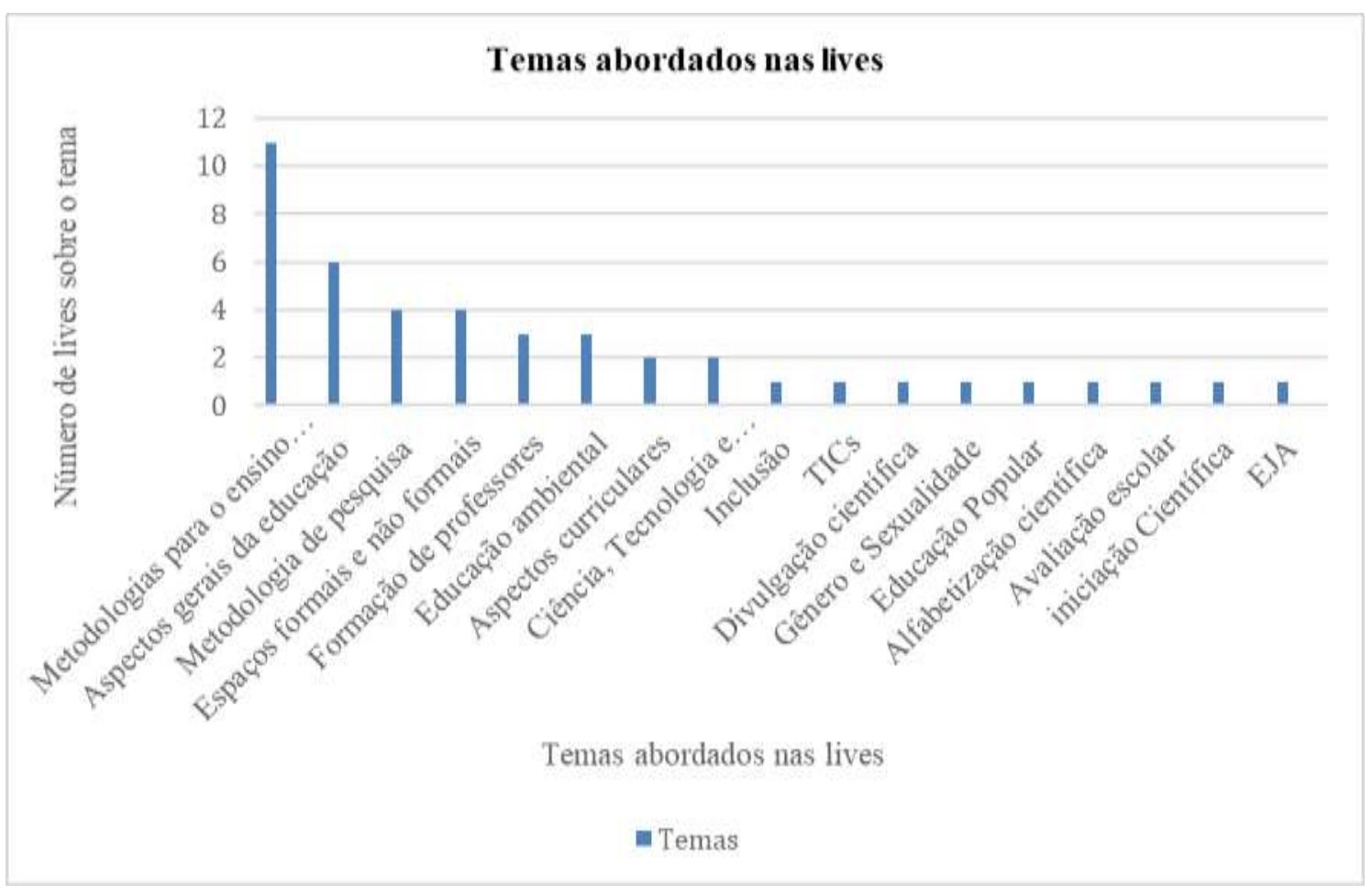

Fonte: Autores (2021).

Conforme pode ser visto acima, houve uma grande diversidade de temas. Esses resultados demonstram a importância dos ciclos para a formação dos sujeitos participantes, pois são assuntos necessários e que contemplam diferentes tipos de atuação docente. Além disso, a discussão dessas temáticas diversas favorece repensar o processo educativo, bem como limitações ainda existentes no cenário educacional.

A utilização da plataforma gratuita permitiu que todos que têm acesso à internet, aparelho de smartphone, televisão smart ou computador, conforme dados acima, participassem, atingindo um público local, regional e nacional. Dessa forma, foi possível criar um debate sobre educação, com foco em Educação em Ciências e a presença de diferentes profissionais da área, de diversos locais, interagindo simultaneamente.

Conforme Bastos (2011), o YouTube como um fórum de discussões online caracteriza-se como um novo ambiente de 
aprendizado auxiliando nos desafios impostos pela sociedade do conhecimento. A autora pontua uma aprendizagem envolvendo a colaboração, discussão, defesa de ideias, a construção de consenso e conhecimento em comunidade.

Em consonância a isso, a viabilidade das formações docentes proporcionada pelo uso das tecnologias digitais, é corroborada por Modelski, Giraffa e Casartelli (2019) quando discutem que o novo cenário social, marcado pelo advento da tecnologia, possibilita a quebra do paradigma da presencialidade, isto é, que as formações e processos educativos ocorram somente de maneira presencial. Por isso, considerando todas as mudanças oriundas nos últimos anos, principalmente, aquelas relacionadas ao uso cada vez mais frequente de tecnologias digitais, torna-se indispensável adaptar-se a essa nova realidade, incorporando espaços virtuais como locais de aprendizagem. Assim, os autores mencionam que é preciso "reaprender, reavaliar nossas concepções relacionadas à formação e à educação" (Modelski, Giraffa \& Casartelli, 2019, p. 2).

Dessa forma, com o desenvolvimento do projeto foi possível propiciar momentos de diálogos e reflexões teóricas e práticas entre educadores sobre diversos temas que permeiam a educação e o Ensino de Ciências. Esperamos ter contribuído com processos de reflexão e formação docente. Além disso, foi possível criar um espaço de formação permanente que permitiu uma aproximação entre a universidade, escolas e a comunidade interessadas no assunto, promovendo experiências formativas em torno da educação básica e superior assentadas na indissociabilidade com o ensino, pesquisa e a extensão.

\section{Considerações Finais}

O presente estudo demonstrou a importância e a necessidade de nos reinventarmos frente aos novos desafios impostos em meio a um cenário de pandemia e isolamento social, pois existem possibilidades viáveis para dar continuidade aos processos de formação docente. A exemplo da utilização das tecnologias digitais, como ferramentas que permitem a acessibilidade em diferentes locais e contextos, além de favorecer a aprendizagem, diálogo e a troca de conhecimentos pelos sujeitos participantes.

A partir dos dados quantitativos apresentados neste trabalho, com a realização dos Ciclos Formativos, observamos que as possibilidades das dimensões espaço/tempo para a formação de professores foram caracterizadas pelo - O Espaço - físico sendo a casa de cada participante da live e o espaço "interacional" - de formação - promovido pelas TDIC. Com isso, as barreiras geográficas foram superadas, sendo que professores, estudantes e comunidade puderam ter acesso às lives nas distintas regiões do Brasil, demonstrando o alcance do canal. A dimensão - Tempo - permitiu a flexibilidade de horário para que as lives fossem assistidas, sendo que os indivíduos puderam assisti-las em tempo real (ao vivo), bem como desfrutaram da possibilidade de acessar as lives em outros momentos. Os indivíduos participaram das lives, principalmente, através dos dispositivos móveis, isto é, dos telefones celulares, o que pode estar atrelado a uma maior praticidade de acesso.

Também, observamos uma predominância do público feminino, o que é interessante, pois sabemos que as mulheres, historicamente, realizam jornadas duplas - o que tem se agravado ainda mais com a pandemia. Todavia, mesmo diante desse cenário social, são justamente as mulheres que demonstram maior interesse nessas formações. Salienta-se que isso pode ter ocorrido de maneira pontual neste projeto ou ainda ser reflexo em outras formações.

Por tudo isso, ao analisar os resultados obtidos a partir do desenvolvimento deste projeto, sinalizamos a importância de se diversificar as formações, incorporando as novas tecnologias digitais. Visto que podem favorecer uma maior praticidade e acessibilidade pelos sujeitos participantes, rompendo com a necessidade da presencialidade. Contudo, é importante refletir que nem todo mundo tem acesso a essas tecnologias, devido a existência de profundas desigualdades sociais, o que implica pensar em alternativas para que cada vez mais os professores e o público em geral tenham acesso a esses recursos.

Por fim, considera-se que existe a pretensão de dar continuidade ao canal, através da realização de lives e o lançamento de entrevistas gravadas, em formato de tempo de $45 \mathrm{~min}$, para que o público interessado possa continuar conciliando as suas diferentes demandas, sem que sejam sobrecarregados e assim, manter a divulgação e o diálogo com a 
comunidade sobre Educação em Ciências.

\section{Referências}

Albuquerque, A., Gonçalves, T. O., \& dos Santos Bandeira, M. C. (2020). A formação inicial de professores: os impactos do ensino remoto em contexto de pandemia na região Amazônica. EmRede-Revista de Educação a Distância, 7(2), 102-123.

Almeida, B. O., \& Alves, L. R. G. (2020). Lives, Educação e Covid-19: Estratégias de interação na pandemia. Interfaces Científicas, 10(1), 149-163, https://doi.org/10.17564/2316-3828.2020v10n1p149-163

Arruda, E. P. (2020). Educação remota emergencial: elementos para políticas públicas na educação brasileira em tempos de Covid-19. EmRede-Revista de Educação a Distância, 7(1), 257-275.

Barbosa, C. M., Junior, J. P. L., Mercado, L. P. L., Silva, Q. M., Costa, R. F., \& Nascimento, S. V. (2007). As tecnologias de informação e comunicação na educação: da resistência à efetiva contribuição na prática pedagógica. In: A. M. Damasceno, L. P. L. Mercado \& N. G. Abreu (Org.) Formando o professor pesquisador do Ensino Médio. Maceió: Edufal.

Barreto, A. (2014). A mulher no ensino superior: distribuição e representatividade. Cadernos do GEA, n. 6. FLACSO, GEA. http://flacso.org.br/files/2016/04/caderno_gea_n6_digitalfinal.pdf

Bastos, M. da A. A.; (2011). O YouTube e o Pensamento de Ordem Superior em Inglês (LE): um estudo com alunos de ensino secundário. Dissertação de mestrado. Especialização em Tecnologias de Informação e Comunicação. Universidade do Minho. Braga, Portugal. http://repositorium.sdum.uminho.pt/bitstream/1822/17822/1/Maria\%20da\%20Ascens\%c3\%a3o\%20Afonso\%20Bastos.pdf

Bezerra, N. P. X., Veloso, A. P., \& Ribeiro. E (2021). Ressignificando a prática docente: experiências em tempos de pandemia. Práticas Educativas, Memórias e Oralidade. 3(2). https://revistas.uece.br/index.php/revpemo/article/view/3917/3701

MEC - Ministério da Educação. (2020). Censo da Educação Superior 2019. INEP - Instituto Nacional de Estudos e Pesquisas Educacionais Anísio Teixeira. Brasília, DF: MEC/INEP. https://download.inep.gov.br/educacao_superior/censo_superior/documentos/2020/Apresentacao_Censo_da_E ducacao_Superior_2019.pdf

Fürkotter, M., \& Morelatti, M. R. M (2008). As tecnologias de informação e comunicação em cursos de licenciatura em Matemática. Periódico do mestrado em Educação da UCDB. n.26. https://www.serie-estudos.ucdb.br/serie-estudos/article/view/204/275

Gatti, B. A., Sá Barreto, E. S., André, M. E. D. A., \& Almeida, P. C. A. de. (2019). PROFESSORES DO BRASIL: Novos cenários de Formação. Brasília, DF: Unesco. https://www.fcc.org.br/fcc/wp-content/uploads/2019/05/Livro_ProfessoresDoBrasil.pdf

Leta. J.; (2003). As mulheres na ciência brasileira: crescimento, contraste e um perfil de sucesso. Estudos Avançados. 17(49). https://www.scielo.br/pdf/ea/v17n49/18408.pdf

Modelski, S., Giraffa, L.M.M., \& Casartelli, A.O. (2019). Tecnologias digitais, formação docente e práticas pedagógicas. Educ. Pesqui., 45 , 1-17.

Moreira, J. A.; Schlemmer, E. Por um novo conceito e paradigma de educação digital online. Revista UFG, 20.

Netshow. (2017). Live streaming: tudo o que você precisa saber sobre essa tecnologia. Netshow.me. https://netshow.me/blog/live-streaming-tudo-o-que-voceprecisa-saber/.

Pandemia aumenta em 40\% o tempo que usuários passam em smartphones, aponta App Annie (2020). Mobile Time. https://www.mobiletime.com.br/noticias/09/07/2020/app-annie-usuarios-ficam-40-mais-tempo-em-aplicativos-na-pandemia/

Porto, K. S. \& Santana, L. S. (2016). Aulas de Streaming: recurso e estratégia didática no ensino à distância de matemática. Revista EaD \& Tecnologias Digitais na Educação, 4, 33-40. <https://ojs.ufgd.edu.br/index.php/ead/article/view/5616/3704>.

Silva, K. K. A. \& Behar, P. A. (2019). Competências digitais na educação: uma discussão acerca do conceito. Educação em Revista, 35 (209940), 1-32. 